\title{
Geotechnical control of tunnel works in Hong Kong
}

Pui Loi Richard Pang PhD, CEng, FHKIE, MICE, MIStructE

Deputy Head of the Geotechnical Engineering Office (Mainland), Civil

Engineering and Development Department, Government of the Hong Kong

Special Administrative Region, People's Republic of China

Hilly topography, intense urbanisation and infrastructure development, combined with limited land availability and a growing awareness of environmental issues, have driven Hong Kong's need to develop its underground space. By the end of 2012, about $460 \mathrm{~km}$ of tunnels had been constructed in Hong Kong. While private projects involving tunnel works have been subjected to statutory control to protect public safety for many years, geotechnical control of government tunnel works was only introduced through a government works policy instruction in 2005. This was one of the outcomes of a government review on the project implementation issues of a deep sewage tunnel project which encountered major construction problems due to adverse geology. The geotechnical control regime which was introduced took account of the development of geotechnical risk management internationally and notable tunnel failures both in Hong Kong and elsewhere. To facilitate geotechnical control, the Geotechnical Engineering Office of the Civil Engineering and Development Department has prepared technical references and guidance documents, including a catalogue of notable tunnel failure case histories. This paper traces the development of geotechnical control of tunnel works in Hong Kong, with a view to help in minimising the risk to life and property posed by construction of tunnel works.

\section{Introduction}

The population of Hong Kong has increased steadily from about $2 \cdot 2$ million in 1950 to more than 7 million today. Hilly topography, intense urbanisation and infrastructure development, combined with limited land availability and a growing awareness of environmental issues have driven Hong Kong's need to develop its underground space.

The geology of Hong Kong, which comprises mainly hard, crystalline, volcanic and granitic rocks, is shown in Figure 1. The land area of Hong Kong is about $1100 \mathrm{~km}^{2}$. About $47 \%$ of the land is greater than $100 \mathrm{~m}$ above sea level, and $12 \%$ exceeds $300 \mathrm{~m}$. There are 32 peaks higher than $500 \mathrm{~m}$, three of which rise above $800 \mathrm{~m}$. The limitations on flat land have necessitated the construction of tunnels and associated underground structures to support Hong Kong's built environment. Other than the rock tunnels through the hills, urban development has led to many tunnels being constructed in soft ground in the low-lying urban and sub-sea areas, as well as the construction of a number of immersed tube tunnels (CEDD, 2008; HKIE, 2007; Massey et al., 2007). Locally, most rock tunnels are excavated by drill and blast, whereas the soft and mixed ground tunnels are constructed by a combination of cut and cover and tunnel boring machines (TBMs). Slurry TBMs as well as earth pressure balance (EPB) TBMs are used. To facilitate tunnel works construction, techniques that incorporate in situ ground treatment, groundwater control, installation of temporary and permanent supports, and so on, are adopted to stiffen and strengthen the ground and to reduce its permeability. The 'tunnel density' in Hong Kong (currently $\sim 0.42 \mathrm{~km}$ of tunnel per $\mathrm{km}^{2}$ of land area) is one of the highest among major world cities, including London and Tokyo.

A Catalogue of Hong Kong Tunnels (GEO, 2013) has been prepared and is periodically updated by the Geotechnical Engineering Office (GEO) of the Civil Engineering and Development Department (CEDD) of the government of the Hong Kong Special Administrative Region (HKSAR). This catalogue disseminates available information on existing tunnels and the tunnels currently under construction in Hong Kong. It also gives references to the technical literature and other information published on these tunnels for reference by the civil and geotechnical engineering profession in Hong Kong. Since the late $1880 \mathrm{~s}$, more than $460 \mathrm{~km}$ of tunnels have been constructed in Hong Kong (Figure 2). This excludes the small-diameter utility tunnels constructed using hand mining, pipe jacking, directional drilling, and so on.

For the purpose of this paper, a 'tunnel' is a long underground passageway with an opening at each end, and the term 'tunnel works' is used to include tunnels, shafts, caverns and associated underground facilities, however constructed. The term 'failure' relates to failure in geotechnical control; although a ground/ structural collapse or large-magnitude ground deformation/ 


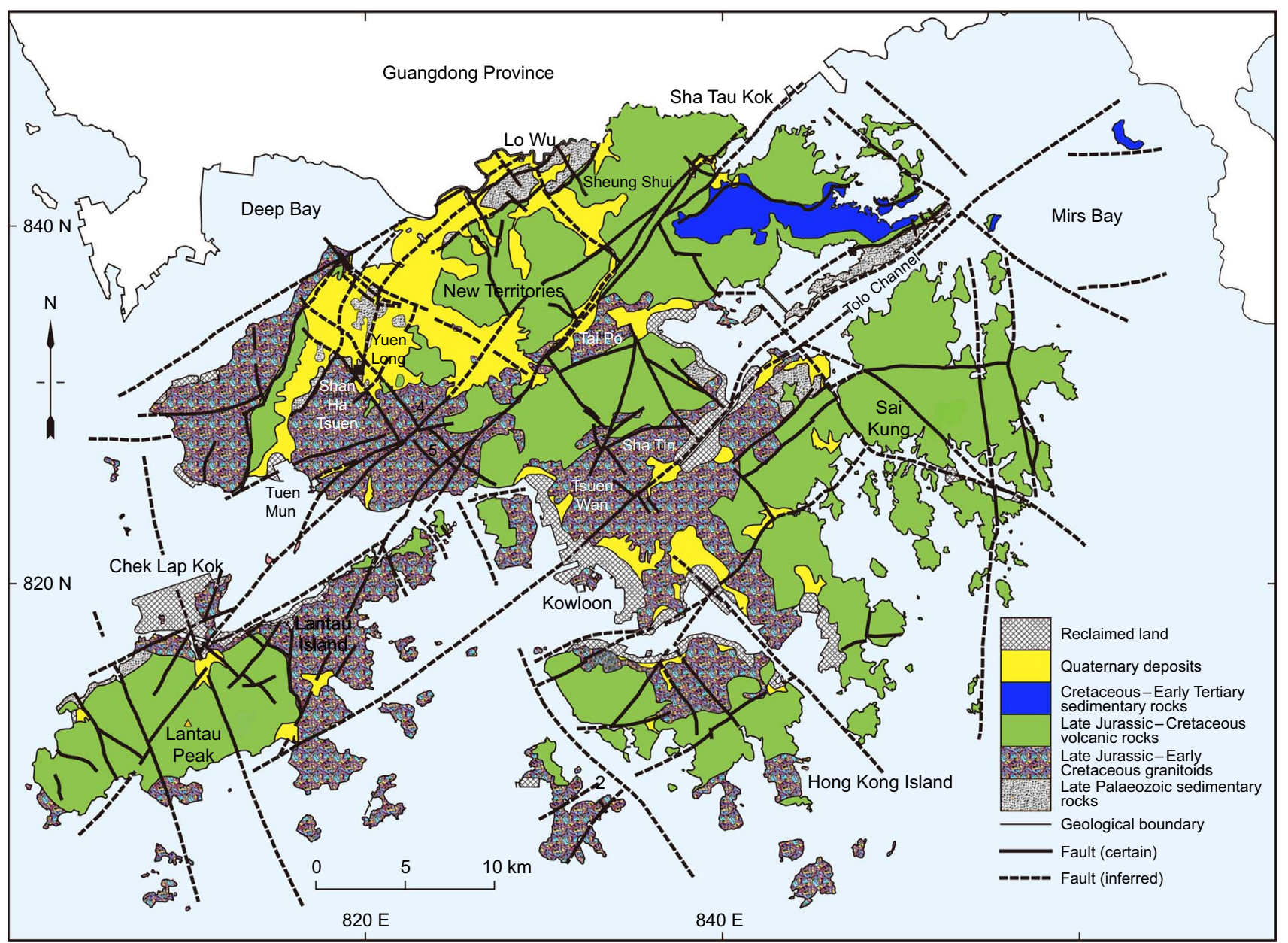

Figure 1. Simplified geological map of Hong Kong (from Sewell et al. (2000))

structural damage arising from tunnel construction can result in dramatic and costly consequences, with major public safety implications, all too often it is the less dramatic but no less significant failures in geotechnical control that can result in major programme and cost overruns to a project.

An outline of the development of geotechnical control for tunnel works in Hong Kong taking into account the lessons learnt from previous tunnel failure cases is presented in this paper.

\section{Geotechnical control regime}

Before the geotechnical engineering profession was established in Hong Kong, geotechnical designs were mainly based on empirical rules. On 18 June 1972, two disastrous landslides occurred. A fill embankment collapsed causing 71 fatalities and a steep hillside failed with 67 fatalities. At the recommendation of the Commission of Enquiry into the incidents, a Civil Engineering Section was set up in the then Buildings Ordinance Office of the Public Works Department to check the geotechnical aspects of private development submissions. Four years later, another landslide occurred on a big embankment, resulting in 18 fatalities. On the recommendation of the Independent Review Panel for Fill Slopes, the Hong Kong government set up the Geotechnical Control Office (now GEO) in 1977. One of the major duties of the GEO is to audit the geotechnical submissions on slopes and retaining walls and the standard of the geotechnical site supervision for new building and civil engineering projects, both in the public and private sectors. The objective is to contain the increase in landslide risk due to the projects. Over the last 36 years, the GEO has established and continuously refined the slope safety system in Hong Kong, under which geotechnical control regulations are introduced, geotechnical standards are set up 


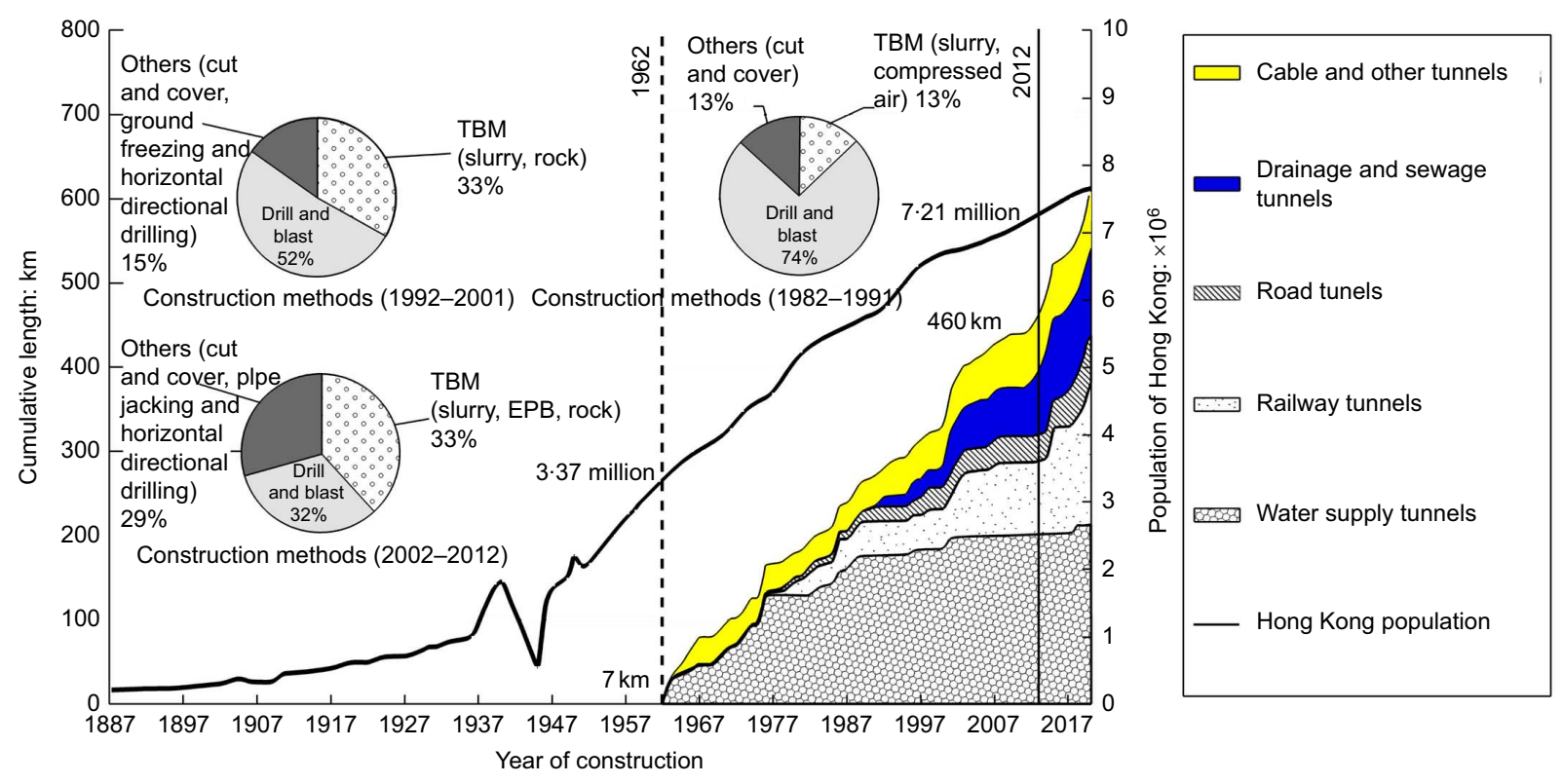

Figure 2. Tunnel development in Hong Kong from 1887 to 2012

and estimated future development (from Sun et al. (2012))

and geotechnical practice is improved in partnership with the local geotechnical practitioners.

Hong Kong had for a long time a Buildings Ordinance (Laws of Hong Kong, Chapter 123 (Department of Justice, 2012)) under which private projects are subjected to statutory control to protect public safety. Under the Buildings Ordinance, 'building' is defined to include 'cavern or any underground space adapted or constructed for occupation or use for any purpose including its associated access tunnels and access shafts'. For government projects involving slopes and retaining walls, an administrative arrangement was put in place through issue of government works policy instructions for GEO to exercise geotechnical control.

Amendments were made to the Buildings Ordinance and Regulations in 1990 for controlling the safety of 'excavation and lateral support works', where approval and consent to start works are required to be obtained prior to construction. This was in response to the collapses and excessive deformations caused by excavations in the 1980s, which included those associated with construction of tunnel works for the mass transit railways in the urban areas.

The GEO carries out audits and advises the Building Authority on the geotechnical aspects of the private projects, including the railway projects constructed by the public authorities or corporations. The scope of the audits covers the geotechnical aspects of designs, and assessment of the effects of proposed tunnel works on adjacent land, services, buildings and other structures/facilities, as well as the standard of site supervision and implementation of geotechnical risk management.

Government projects involving tunnel works were not subjected to geotechnical control, statutory or otherwise, until 2005.

\section{The Harbour Area Treatment Scheme (HATS) Stage I project}

The Harbour Area Treatment Scheme (HATS), previously known as the Strategic Sewage Disposal Scheme (SSDS), is an overall sewage collection, treatment and disposal strategy to deal with the water pollution of Hong Kong's Victoria Harbour. Implementation of HATS was divided into four stages.

Construction of the HATS Stage I project began in early 1995. It involved the provision of a system of deep tunnels $23.6 \mathrm{~km}$ long for transporting sewage collected from a number of catchments around Victoria Harbour to a treatment works on Stonecutters Island. The tunnels were excavated largely beneath the sea at depths unprecedented in Hong Kong, ranging from $80 \mathrm{~m}$ to $150 \mathrm{~m}$ below sea level. They were mainly in rock with a minimum cover of $30 \mathrm{~m}$ in Grade III or better rock. At the time of design, the rock was believed to be of good quality and relatively impermeable, and hence suitable for deep 


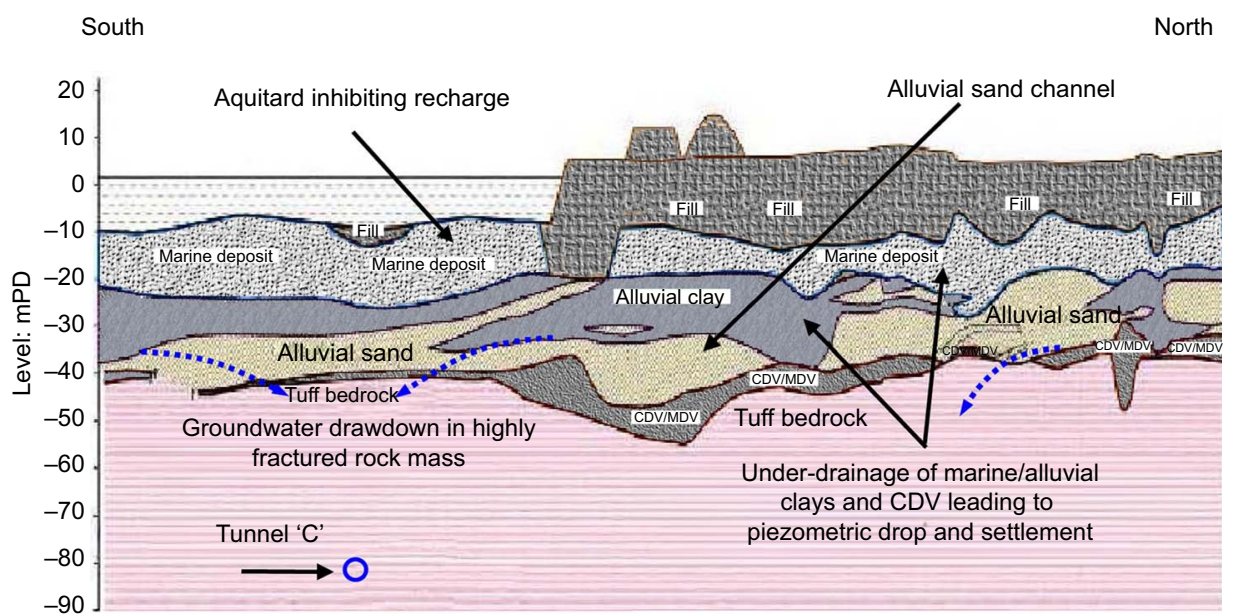

(a)

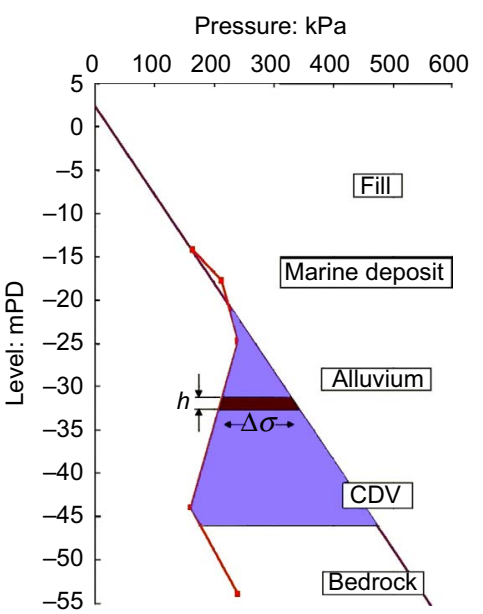

(b)

Figure 3. Groundwater drawdown in the HATS Stage I Project (from Pang (2011)) (CDV: completely decomposed volcanic tuff; MDV: moderately decomposed volcanic tuff; mPD:metres above principal datum): (a) cross-section showing geological profile;

(b) piezometric pressure reduction

tunnel construction, and an open-mode TBM was considered a suitable method of construction. The original target completion date for HATS Stage I was June 1997.

During construction, serious problems arose due to heavy water inflow into sections of the tunnels (McLearie et al., 2001). In addition to construction problems within sections of the tunnels, the water inflow led to extensive drawdown of the groundwater. In one section, significant ground settlements (up to $1.2 \mathrm{~m}$ ) occurred up to $1.8 \mathrm{~km}$ from the tunnel alignment, resulting in major impacts on the community and major public concern. There was significant delay to completion of the project (about 4.5 years late) and a substantial increase in cost (an extra $\sim \mathrm{HK} \$ 2 \cdot 3$ billion compared with the original sum of $\sim \mathrm{HK} \$ 6 \cdot 2$ billion $(\mathrm{HK} \$ 1=£ 0 \cdot 079)$ ). The extent and magnitude of these socio-economic impacts led to a review of the project by the Director of Audit (2004) and the Public Accounts Committee (LegCo, 2004a). In essence, the delay and cost increase were attributed to problems in constructing the sewage tunnel system: difficult ground conditions due to adverse geology, major breakdowns in machinery and the forfeiture of two of the original tunnel contracts.

The then Environment, Transport and Works Bureau (ETWB) of the government of the HKSAR, assisted by the Drainage Services Department and the GEO, conducted a review of the implementation issues of the HATS Stage I project. On technical aspects, the review indicated that the significant settlements were due to a reduction in the piezometric pressures causing an increase in effective stresses, which led to consolidation of the compressible soils overlying the rock mass. The reduction in piezometric pressures resulted from large groundwater drawdown in the rock mass due to the heavy water inflow into the tunnels (Figure 3 ). The rock mass had a network of discontinuities (e.g. fault and fracture zones) and hence a high mass permeability, which conveyed groundwater to the tunnels from sources at a long distance away. On risk allocation and management, the review indicated that

Government [in future] will share the risks with contractors, and suitable contract terms will be introduced to the effect that the contractors will be recompensed for additional expenses and time spent if ground conditions encountered are worse than expected

and

To improve the identification and management of risks in ground conditions in future projects, designers will in future be required to provide a comprehensive risk management plan at the design stage.

The findings and recommendations, including those mentioned above, were reported to the then Legislative Council Panel on Planning, Lands and Works in June 2004 (LegCo, 2004b). Following this review, a series of specific recommendations and associated implementation plans were developed, which involved improvements to public works policy and procedures and development of technical guidance documents. 
The specific recommendations relating to the geotechnical aspects of government projects involving tunnel works were as follows.

(a) In planning ground investigation for future tunnel projects, consideration should be given to the use of new technology such as directional coring.

(b) Where consultants are selected for major tunnel projects, more weight should be placed on their geological and tunnelling knowledge and experience and their familiarity with the local ground conditions.

(c) GEO (in particular, the Hong Kong Geological Survey in the GEO) should be consulted on planning and interpretation of ground investigations, ground modelling and hydrogeological modelling, identification of problematic areas, and verification of geological features during construction.

(d) Designers should be required to carry out detailed assessments at the design stage to estimate the magnitude and extent of ground settlement due to the proposed tunnel works.

(e) The assessment of the magnitude and extent of ground settlement due to the proposed tunnel works should be reviewed by the GEO before tendering.

(f) Mandatory requirements on documentation of the geotechnical design should be imposed to facilitate verification of design assumptions through monitoring and, if necessary, modification of design or specifications during construction.

(g) All geological information revealed from future tunnel projects should be passed to GEO for use in updating published geological maps and preparing new maps.

\section{Government works policy instructions}

Following the HATS Stage I project implementation review, a number of government works policy instructions were issued (Pang, 2011; Pang and Woodrow, 2009). These have an important bearing on the management of geotechnical risks for projects involving tunnel works.

An important, directly relevant policy instruction issued is ETWB TC(W) No. 15/2005, on 'Geotechnical control for tunnel works' (ETWB, 2005b). Under this circular, the GEO audits the geotechnical aspects of design submissions on government tunnel works and the adequacy of the project's site supervision and geotechnical risk management provisions. The GEO also conducts site audits on the implementation aspects. The scope and focus of these audits are to protect public safety. This parallels the GEO's role to exercise geotechnical control of private sector tunnel works under the Buildings Ordinance. In addition to the GEO undertaking technical audits, project offices are required to consult the GEO at various project stages before tendering. During the consultation and auditing processes, the GEO serves in the capacity of a geotechnical advisor and provides geotechnical advice to the government project office.

In formulating its public works policy to enhance the standard of risk management for tunnel works, the government of the HKSAR recognises the need to utilise its in-house geotechnical expertise to provide advice to its project offices, independent of the parties directly involved in implementing and managing the project/contracts. It also recognises the need for its project offices to seek specialist geotechnical advice throughout the project, as opposed to ad hoc advice when problems arise. As a good understanding of geology is essential for managing the ground risks inherent in construction of tunnel works, the ETWB circular requires the project offices to consult the Hong Kong Geological Survey in the GEO at an early stage of the project development.

Two other important related policy instructions were also issued. The first one is ETWB TC(W) No. 17/2004, on 'Impossibility/unforeseen ground conditions/utility interference' (ETWB, 2004). It acknowledges that the government of the HKSAR

being a long term employer in the construction and maintenance of major infrastructures, will in the long run bear all the costs of the works, including the cost of the risks, either under the same contract or in subsequent contracts as these risks and the associated costs are inevitably reflected in the tender price.

It is therefore in the interest of the government of the HKSAR to reduce these risks or to minimise the overall cost of the risks wherever practicable.

The policy instruction states that

project officers should arrange to carry out all necessary site investigations and satisfy themselves that sufficient ground information has been made available prior to commencement and during the detailed design. The extent of ground investigation and/or geotechnical analysis should be adequate for estimating construction cost and duration to an acceptable degree of accuracy.

It advises that 'project officers should consider to adopt remeasurement approach for underground works ... which may have a significant bearing on the cost of the contract', and 'where unforeseen ground conditions might have a substantial impact on the required temporary works, consideration may be given to provide separate items in the $\mathrm{BQ}$ for these temporary works'. It also advises that 'the best way to minimise the risks of a contract is to ensure that there exists a reasonably workable solution in compliance with the contract requirements'. This advice is particularly valuable for projects 
involving major tunnel works where a design and build form of contract is adopted, or where a conventional form of contract is adopted but with sections of major tunnel works and associated temporary works (to be designed by the contractor) that require substantial costs to construct, and construction of such works is on the critical path of the contract programme. A reference design, which is workable and is sufficient to allow estimation of the construction cost and duration to be made to an acceptable degree of accuracy, should be carried out prior to tendering.

The second related policy instruction is ETWB TC(W) No. 6/ 2005, on 'Implementation of systematic risk management (SRM) in public works projects' (ETWB, 2005a). It requires that

SRM should be carried out for all public works programme projects with cost estimates exceeding HK\$200 million (about US\$26 million) throughout the project period except for those projects ... which are of routine nature; primarily straightforward; and/or unlikely to attract interfacing problems or objections.

This circular is the outcome of a review of international risk management practice. An approach has been developed to manage risks on public works projects in a systematic manner; geotechnical risk management has to be an integral component of the SRM for the overall project. The SRM approach entails risk analyses to be taken at regular intervals during project implementation. This allows continuous monitoring of the risk exposure of the project, allocation of responsibility to the party best able to manage the identified risk, and assessment of the effectiveness of risk control measures. Specific guidance on the application of the risk management process to public works programme projects is provided in a risk management user manual (ETWB, 2005a). Works departments are required to continue to estimate the expected values of risk associated with their projects in assessing the contingency to the capital cost of a project for project estimate purposes.

In implementing the geotechnical control for tunnel works under EWTB TC(W) No. 15/2005, the GEO advises the project office to employ adequate qualified design staff as well as geotechnical site supervision staff with relevant experience, carry out sufficient pre-tender ground investigation and risk assessments to define the scope of the ground control and risk mitigation works required, incorporate robust ground control and risk management provisions in the contract specifications, define clearly the ownership of design and risk management, and allow sufficient time in the contract programme for carrying out the necessary ground control and risk mitigation works, and making submissions to GEO. GEO maintains close liaison with the project office and its consultants to agree the schedule and priority of submissions to GEO for audit, including those to be made during construction; provides feedback on the proposed design scheme, geotechnical risk and 'buildability' of the risk mitigation works; and clarifies and resolves with the submitter and project office promptly the technical issues arising from the audits carried out in the geotechnical control process. GEO's audits do not change the authority, duties, responsibilities and liabilities of the project office and its agents responsible for the project.

\section{Geotechnical guidance documents and references}

In order to facilitate the geotechnical control of tunnel works, GEO has prepared two technical guidance notes (TGNs) to supplement the 'Geoguides' and the series of TGNs it has published. A Catalogue of Hong Kong Tunnels (GEO, 2013), a Catalogue of Notable Tunnel Failure Case Histories (GEO, 2012) and a GEO report on Ground Control for Slurry TBM Tunnelling (GEO, 2009) have also been published.

\subsection{Site investigation}

GEO TGN24 (GEO, 2005a) is the first geotechnical guidance document issued to address the recommendations of the HATS Stage I review. It provides guidance on specific aspects of site investigation for tunnel works, and supplements previous guidance given in Geoguide 2 (GCO, 1987) and Geoguide 4 (GEO, 1992). In essence, its purpose is to prompt project clients and their designers to consider carefully, at an early stage of the project, the scale and type of ground investigation (and the associated geotechnical assessment) required for a project involving tunnel works. This is to ensure that a proper early assessment is made of the level of geotechnical risks associated with the ground conditions, in order to optimise the choice of tunnel alignment and design, to allow adequate design/reference design to obtain a clear definition of the scope of works and the likely funding and programme required, and to minimise the risks to the programme, cost and impact of the works on life and property.

For major tunnel projects in difficult ground, wrong interpretation of ground investigation results by the contractor can lead to miscalculation of the ground risk and submission of an unrealistically low tender price. Also, with competitive tendering, the contractor may take unrealistically high risk (unacceptable to the client) in order to win the contract, and there could be inadequate or no allowance made in the tender price and programme for carrying out geotechnical risk mitigation works to an acceptable safety standard. This could increase public safety risk. It could also increase the probability of contractual claims or even forfeiture of the contract. Therefore, timely availability of adequate ground investigation data and ensuring that the tenderers make proper interpretation and use of this information in their tender submission, for example by making available a 'geotechnical baseline report' (ASCE, 
2007), a 'differing site conditions' clause and other contract provisions, such as for reimbursement of payment for risk mitigation works and extension of time where these are justified, should be key components of the overall risk mitigation strategy.

The TGN recommends that interpretative geotechnical reports, in a form that will meet the needs of professional users, should be prepared using the data obtained during the various phases of the site investigation, and that in these reports any previous relevant interpretative reports should be updated. Project managers are advised to arrange to carry out all necessary site investigations and satisfy themselves that sufficient ground investigation information is available prior to the start of the contract and during the reference design and detailed design.

The TGN recognises that, in some cases, access, time and other constraints limit the extent of pre-contract ground investigation and that, even with the best investigation, much in the way of ground information inevitably remains unknown until excavation of the tunnel works is underway. Therefore, where there remains significant uncertainty with the ground conditions prior to tender, the project client (or the contractor) may need to undertake additional ground investigation in a timely manner during the construction stage. Additional ground investigation such as 'probing ahead' (sufficiently far ahead of the tunnel face) during construction, to identify the need for measures to mitigate potential ground hazards and risks, is recommended to be carried out.

\subsection{Geotechnical risk management}

At around the time of the HATS Stage I review, systematic identification and management of construction risks was becoming increasingly common practice in many areas of the construction industry. In some jurisdictions, this became a regulatory requirement as part of construction site safety management requirements, for example, the UK's Construction (Design and Management) Regulations 2007 (HMSO, 2007). In Hong Kong, the report Construct for Excellence (CIRC, 2001) has highlighted the need to adopt similar practices in Hong Kong's construction industry and recommended the public sector clients to take a lead in promoting wider adoption of systematic risk management to improve project performance.

With regard to tunnel works, a review of the technical literature indicates that many problems, particularly those that result in a direct impact on the public, are due to inadequacies in the management of geotechnical risks. These geotechnical risks are either, as Barton (2004) has suggested, often a result of an unexpected combination of factors or the unexpected magnitude of a single factor. Such incidents have resulted in significant losses to clients, contractors, consultants and the insurance companies. The insurers' perception was that the tunnelling industry had an inconsistent approach to risk management, to the extent that it threatened the provision of insurance coverage to the tunnelling industry as a whole (Mellors and Southcott, 2004). As a way forward, the insurers worked with the tunnelling industry to develop a 'Joint code of practice for risk management of tunnel works', which was published by the Association of British Insurers and the British Tunnelling Society in 2003. This became the forerunner of the international code entitled $A$ Code of Practice for Risk Management of Tunnel Works published by the International Tunnelling Insurance Group (ITIG, 2012).

The code of practice emphasises the importance of risk management in all stages of a project, that is, project development, construction and contract procurement, design, and construction stages. It promotes identification of hazards and the associated risks during all four stages, preparation of risk registers, cascading the registers throughout the project to ensure that all parties are aware of the previously identified hazards and risks, continuous review and updating of the registers throughout the project, and identification of a party to be responsible for managing each element of risk. It highlights the need for the project client to take proactive action and responsibility in risk management. It also requires the project client to carry out adequate ground investigation and to prepare (or have prepared on its behalf by a competent agent) 'ground reference conditions' for projects involving tunnel works.

In view of the development, GEO issued a second geotechnical guidance document TGN25 (GEO, 2005b). This refers to, and has incorporated the essential elements of, the international code of practice for risk management of tunnel works.

From the HKSAR government's perspective as a regulator, a key aim of geotechnical risk management in tunnel works is to ensure that the works do not impact adversely on public safety. To help achieve this, TGN25 advises that it is the responsibility of the project client, with due advice from the project manager and an experienced geotechnical professional, to ensure that adequate resources are provided and an adequate system is in place for the management of geotechnical risks in the construction of such works. The implementation details should take into account the level of risk to life and property. The TGN advises that insurance of the risk does not remove the need, or reduce the responsibility of the client, to ensure safety is properly managed.

Some geotechnical risks are related to the design or construction method. Consequently, evaluation of the tunnel alignment, layout design and construction methods is an 
important step in managing such risks, in that exclusion of particular layout designs or construction methods could avoid specific risks. In some cases, the contract may need to exclude designs or construction methods that are not acceptable based on risk management considerations.

\subsection{Catalogue of notable tunnel failure case histories}

As part of the work to support the development of policy and implementation of geotechnical control, GEO has collected and reviewed literature on notable tunnel failures with ground collapse, large groundwater inflow or major public consequences reported. Based solely on the literature, it is difficult to assess fully the extent of the problems associated with tunnel works; many cases are likely to be unreported for contractual and legal reasons. Even for the cases where there are public reports of the major consequences, details (in particular the causes) are often not available. Concern from the insurance industry, however, indicates that, worldwide, large insurance claims have been made all too frequently. Only a few investigations of forensic quality have been conducted, and the following documents give useful insights.

The Health and Safety Executive (HSE, 1996), in its review of safety of new Austrian tunnelling method (NATM) tunnels, presents data on 39 significant NATM incidents worldwide. It indicates that many projects have experienced multiple collapses. The incidents were not confined to countries with little prior experience of NATM. The consequences of tunnel collapse for the public, infrastructure and the built environment are consistently high in urban areas. HSE has classified the causes into five broad categories: unpredicted geological causes, planning and specification mistakes, calculation or numerical mistakes, construction mistakes, and management and control mistakes.

The Committee of Inquiry into the Nicoll Highway cut and cover tunnel collapse in Singapore on 20 April 2004 (Government of Singapore, 2005) has identified several technical and administrative errors, which contributed to the collapse. It points to the need for robust design, risk management, design review and independent checking, purposeful back analysis, an effective instrumentation, monitoring and interpretation regime, an effective system of management of uncertainties and quality during construction, corporate competencies and safety management. It also recognises that the safety of temporary works is as important as that of permanent works and should be designed according to established codes and checked by competent persons. The Building Control Authority of Singapore has subsequently published enhanced guidelines on design and construction control of deep excavations (BCA, 2005). The Singapore government has introduced a range of measures to regulate the geotechnical aspects of building works, which include legislation for a new category of professional registration for geotechnical engineers under the Professional Engineers Act, requiring underground building works to be certified by professional engineers (geotechnical), and mandating under the Building Control Act that designs of underground building works are to be checked by specialist accredited checkers (geotechnical).

Recognising the usefulness of the information collected, GEO decided to prepare a Catalogue of Notable Tunnel Failure Case Histories (GEO, 2012). The first edition was published in 2005. The catalogue, which is freely available on the CEDD website, is primarily based on published information. The professionals in Hong Kong, including GEO staff and members of the Hong Kong Institution of Engineers (HKIE) Geotechnical Division's working group on cavern and tunnel engineering, as well as interested professionals from other countries, have provided much useful information. Both international and local cases involving collapse or excessive deformation of the ground are included. For contractual and other reasons, there are relatively few cases reported in technical publications, and those reported are usually of such scale or seriousness that they have received public attention. Apart from the cases included, a list of references is given in the catalogue for readers to follow up.

The main purpose of the catalogue is to disseminate information and promote awareness on tunnel failures which could pose a danger. The possible causes of the failures, the geotechnical problems and the lessons learnt, where these are known, are outlined. Readers are advised to refer to the source reference documents quoted for details. Clients and works agents are advised to implement effective geotechnical risk management measures in the planning, investigation, design and construction of their tunnel projects.

Up to the time of writing, the catalogue has included information on 52 international and six notable local cases, which occurred in the period from 1964 to 2012. It also includes photographs and illustrations, as well as the source references. Based solely on these case histories, many people were injured or lost their lives as a result of tunnel collapses, a number of building evacuations took place involving hundreds of people, many buildings and major roads were damaged and closed, and tens of thousands of people were affected. Many of the failures were due to insufficient ground investigation to locate the soil/rock interfaces or areas of problematic ground above and ahead of the tunnel excavation face, poor identification of geotechnical risks, especially the brittle failure modes, lack of documented design calculations, inadequate risk monitoring and interpretation regime, and inadequate risk management. Knowledge of these failures could help designers 
Variable rockhead and mixed ground conditions

Presence of buried obstructions or voids (e.g. corestones, boulders, disused piles, old seawalls, cavities in karst and other artefacts) Presence of foundations and other subsurface installations Presence of permeable zones that may be subject to high groundwater pressure or that may convey large quantities of inflow Presence of weak or compressible ground (e.g. weak/fractured zones, faults, fissures, clay-coated discontinuities, granular soils and soft/ compressible soils). Ground under very high or very low in situ stress Presence of explosive or poisonous gas (e.g. methane) or other aggressive chemicals

Salinity of groundwater

Contaminated ground (e.g. due to ingress of leachate from landfill)
Avoid/reduce the risk; for example, by selecting a suitable tunnel alignment based on adequate site investigation

Reduce the risk; for example, by specifying or selecting appropriate tunnelling method(s) with adequate additional site investigation during construction

Treat the risk; for example, by specifying appropriate ground support (e.g. precast segmental linings with back grouting), ground strengthening, groundwater control and containment measures, and implementing preventive or protective works

Table 1. Typical examples of geotechnical hazards in tunnel construction (GEO, 2005b)

and contractors to be more vigilant and to avoid making the same mistakes. A table synthesising typical examples of geotechnical hazards and construction-method-related risks in tunnel construction has been prepared (see Tables 1 and 2) and included in GEO TGN25.

The catalogue is a live document, which will be updated from time to time as further information becomes available, for knowledge management to serve the profession.

\subsection{Report on ground control for slurry TBM tunnelling}

Two local tunnel failures mentioned in the catalogue are briefly described below. These incidents did not cause any injury but were 'near misses' as they occurred in urban areas and could have caused serious consequences if they had taken place at a busy time.

In the late hours of 20 October 2006, 7 days after the start of the slurry TBM tunnelling for a major railway project in Hong Kong, a sinkhole was formed with a $3.5 \mathrm{~m}$ diameter crater exposed at the ground surface. The TBM had advanced $8 \mathrm{~m}$ beyond the launching shaft and just outside the jet grout block. A reduction in slurry pressure below the groundwater pressure was recorded. The seal ring at the 'soft eye' for TBM entry had failed. Owing to blockage of fibre glass from the soft eye, the slurry treatment plant could not provide the bentonite slurry pressure required to stabilise the ground. Also, the design length of the jet grout block for the TBM breakout at the launching shaft was found to be insufficient.

In the early hours of 3 June 2007, in the same project, another sinkhole was formed with a crater of about $3 \mathrm{~m}$ diameter exposed at the ground surface. Compressed air intervention was being carried out for cutter maintenance, when the slurry TBM intersected a shallow dipping interface between the completely/highly decomposed granite and the overlying marine sand deposits. High air loss was recorded despite the fact that fresh bentonite transfusion was carried out to enhance tunnel face stability prior to the intervention. This incident indicates the high risk associated with compressed air intervention carried out close to interfaces with untreated 'poor' ground.

Following these two incidents, GEO, with the assistance of Golders Associates (HK) Ltd, prepared a guidance document, namely GEO report no. 249 on Ground Control for Slurry TBM Tunnelling (GEO, 2009). The report provides guidelines for the auditing of the design calculations and work procedures relating to ground control during slurry TBM tunnelling. It supplements the BTS/ICE (2005) guideline. The focus is on key issues that affect the magnitude of ground movement due to tunnelling, and therefore the potential impact on third parties. For the first time, the partial factor limit state approach is introduced for effective stress and total stress calculations of TBM face support pressures, taking into account ultimate and serviceability limit state conditions.

GEO is currently working with the HKIE Geotechnical Division's working group on cavern and tunnel engineering to prepare a guidance document on ground control for EPB TBM tunnelling.

\section{Conclusion}

This paper summarises the work of the GEO in the last decade on development of geotechnical control for tunnel works to 
Excessive ground settlement/lateral displacement due to ground loss (including rock falls within the tunnel, tunnel face collapse and loss of soil into surrounding voids) or inadequate ground support caused by unsuitable tunnel construction method/equipment/control measures Excessive ground settlement/lateral displacement due to groundwater inflow/drawdown caused by inadequate tunnel construction method (e.g. pre-grouting not carried out in difficult ground), inadequate ground treatment or groundwater control, or inadequate consideration of changes in ground stresses or groundwater regime Excessive ground vibration

Ejection of rock and protective material (e.g. blast door) at the tunnel portal or areas with a thin ground cover, due to explosion and/or gas pressures

Blow out or ground heave for tunnelling under high compressed air or slurry or grouting pressure
All methods

All methods

All methods that use vibratory equipment, or that could induce ground vibration such as drilling and blasting Drilling and blasting

All methods that create pressure in the ground (e.g. compressed air or slurry TBM and grouting)

Table 2. Typical examples of geotechnical risks in tunnel construction (GEO, 2005b)

protect public safety, in preparedness for a new era of tunnel construction in Hong Kong.

A review carried out by the GEO has indicated that regulatory control is tightened whenever there are serious adverse consequences to the community. In Singapore, legislative changes were introduced to regulate the geotechnical aspects of underground building works following failure of a cut and cover highway tunnel in 2004, which resulted in fatalities. In Hong Kong, geotechnical control of government tunnel works was introduced in 2005, following serious geotechnical problems encountered in a deep sewage tunnel project, which resulted in major impacts on the community and project implementation.

Collection of information on notable tunnel failures has been found to be very useful, not just for understanding the technical causes but also the related management system problems. This work has revealed that many major tunnel failures have occurred worldwide, in many different countries and jurisdictions, including where tunnelling and geotechnical expertise input is expected. They resulted in serious public consequences and major losses, to the extent that insurers found it necessary to work with the tunnelling industry to develop an international code of practice for risk management, to set minimum standards for taking on insurance.

The catalogue of notable tunnel failure case histories prepared by the GEO has helped to raise the awareness of designers and constructors in Hong Kong on what could go wrong, in both technical and management aspects. It is to be hoped that the parties responsible for the planning, investigation, design, tendering and construction of tunnel works will take into account the lessons learnt.

A review of the notable tunnel failures has indicated the need for enhancing the approach and process of site investigation and geotechnical risk management, and for developing technical standards and guidance on tunnel works site investigation, design and risk management.

Formulation of government policy, procedures and technical guidance, supplemented by a formal regime of geotechnical control with review of designs and standard of site supervision, as well as site audits, by a party independent of those responsible for project delivery, are important and useful for minimising the risk to public safety posed by construction of tunnel works.

Preparation of technical guidance and reference documents in partnership with the profession has been found to be worthwhile in achieving consensus in the standards to be adopted.

\section{Acknowledgements}

The author would like to acknowledge his colleagues, in particular, Ir Dr Lorne Woodrow, Ir Dr Thomas Lam, Ir NF Chan, Ir Vincent Tse and Ir Patrick Chau, for their invaluable contributions in the development of geotechnical control for 
tunnel works in the interest of protecting public safety, and in the preparation and maintenance of the related guidance documents and references. This paper is published with the permission of the Head of the Geotechnical Engineering Office and the Director of Civil Engineering and Development.

\section{REFERENCES}

ASCE (2007) ASCE Geotechnical Baseline Reports for Construction - Suggested Guidelines. Technical Committee on Geotechnical Reports, Underground Technology Research Council, American Society of Civil Engineers, Reston, VA, USA.

Barton N (2004) Risk and risk reduction in TBM rock tunnelling. Proceedings of the ISRM International Symposium, 3rd ARMS, Kyoto, Japan, pp. 29-38.

BCA (Building Control Authority) (2005) Advisory Note 1/05 on Deep Excavation. Building Engineering Division, Building Control Authority, Singapore.

BTS/ICE (British Tunnelling Society/Institution of Civil Engineers) (2005) Closed-face Tunnelling Machines and Ground Stability: A Guideline for Best Practice. British Tunnelling Society and the Institution of Civil Engineers, Thomas Telford, London, UK.

CEDD (Civil Engineering and Development Department) (2008) Tunnel engineering. In Construction Management and Civil Engineering Practice in Hong Kong. Association of Engineering Professionals in Society, Hong Kong, ch. 10, pp. 271-304. See http://www.aesnet.com.hk/ publications/articles/1115 (accessed 13/01/2014).

CIRC (Construction Industry Review Committee) (2001) Construct for Excellence. Report of the Construction Industry Review Committee, Hong Kong. See http://www.legco.gov.hk/ yr00-01/english/panels/plw/papers/plw0611-487e-scan.pdf (accessed 13/01/2014).

Department of Justice (2012) Chapter 123 Building Ordinance. Department of Justice, Hong Kong. See http://www. legislation.gov.hk/eng/home.htm (accessed 21/01/2014).

Director of Audit (2004) Harbour Area Treatment Scheme Stage I. Audit Commission, Hong Kong, Report No. 42 of the Director of Audit, ch. 3. See http://www.aud.gov.hk/ pdf_e/e42ch03.pdf (accessed 13/01/2014).

ETWB (Environment, Transport and Works Bureau) (2004) Impossibility/Unforeseen Ground Conditions/Utility Interference. Environment, Transport and Works Bureau, Hong Kong SAR Government, Technical Circular (Works) No. 17/2004. See http://www.devb.gov.hk/filemanager/ technicalcirculars/en/upload/66/1/C-2004-17-0-1.pdf (accessed 13/01/2014).

ETWB (2005a) Implementation of Systematic Risk Management in Public Works Projects. Environment, Transport and Works Bureau, Hong Kong SAR Government, Technical Circular (Works) No. 6/2005. See http://www.devb.gov.hk/
filemanager/technicalcirculars/en/upload/8/1/C-2005-15-01.pdf (accessed 13/01/2014).

ETWB (2005b) Geotechnical Control for Tunnel Works.

Environment, Transport and Works Bureau, Hong Kong SAR Government, Technical Circular (Works) No. 15/2005, see http://www.devb.gov.hk/filemanager/technicalcirculars/ en/upload/8/1/C-2005-15-0-1.pdf (accessed 13/01/2014).

GCO (Geotechnical Control Office) (1987) Geoguide 2: Guide to Site Investigation. Geotechnical Control Office, Civil Engineering Services Department, Hong Kong.

GEO (Geotechnical Engineering Office) (1992) Geoguide 4: Guide to Cavern Engineering. Geotechnical Engineering Office, Civil Engineering Department, Hong Kong.

GEO (2005a) Site Investigation for Tunnel Works. Geotechnical Engineering Office, Civil Engineering and Development Department, Hong Kong, Technical Guidance Note No. 24 (TGN24), updated in 2009. See http://www.cedd. gov.hk/eng/publications/guidance_notes/doc/TGN24.pdf (accessed 13/01/2014).

GEO (2005b) Geotechnical Risk Management for Tunnel Works. Geotechnical Engineering Office, Civil Engineering and Development Department, Hong Kong, Technical Guidance Note No. 25 (TGN25), updated in 2009. See http://www.cedd.gov.hk/eng/publications/guidance_notes/ doc/TGN25_2a.pdf (accessed 13/01/2014).

GEO (2009) Ground Control for Slurry TBM Tunnelling. Civil Engineering and Development Department, Geotechnical Engineering Office, Hong Kong, GEO Report No. 249. See http://www.cedd.gov.hk/eng/publications/geo_reports/ geo_rpt249.htm (accessed 13/01/2014).

GEO (2012) Catalogue of Notable Tunnel Failure Case Histories (Up to October 2012). Civil Engineering Development Department, Geotechnical Engineering Office, Hong Kong. See http://www.cedd.gov.hk/eng/publications/geo/ notable_tunnel.htm (accessed 13/01/2014).

GEO (2013) Catalogue of Hong Kong Tunnels (Up to June 2013). Civil Engineering Development Department, Geotechnical Engineering Office, Hong Kong. See http://www.cedd.gov. hk/eng/publications/geo/hktunnel.htm (accessed 13/01/2014).

Government of Singapore (2005) Report of the Committee of Inquiry into the Incident at the MRT Circle Line Worksite that led to the Collapse of Nicoll Highway on 20 April 2004, Vols 1 and 2. Land Transport Authority, Government of Singapore, Singapore.

HKIE (Hong Kong Institution of Engineers) (2007) Tunnels and caverns in Hong Kong. Invited paper. In Commemorative Volume of the 40th Anniversary of the Southeast Asian Geotechnical Society, Kuala Lumpur, Malaysia.

HMSO (2007) The Construction (Design and Management) Regulations 2007, No. 320. HMSO, London, UK.

HSE (Health and Safety Executive) (1996) Safety of New Austrian Tunnelling Method (NATM) Tunnels. Health and Safety Executive, Bootle, UK. 
ITIG (International Tunnelling Insurance Group) (2012) A Code of Practice for Risk Management of Tunnel Works, 2nd edn. International Tunnelling Insurance Group (in Association with the Munich Re Group). See http://www. britishtunnelling.org.uk/downloads/2013/ITIG_TCOP 01_05_2012.pdf (accessed 20/01/2014).

LegCo (2004a) Harbour Area Treatment Scheme Stage 1. Legislative Council, HKSAR, Hong Kong, Public Accounts Committee (PAC) Report of 23 June 2004, ch. 3. See http://www.legco.gov.hk/yr03-04/english/pac/reports/ 42/ch3.pdf (accessed 13/01/2014)

LegCo (2004b) Review of Project Implementation Issues of Harbour Area Treatment Scheme (HATS) Stage. Legislative Council, HKSAR, Hong Kong, paper for discussion by Legislative Council Panel on Planning, Lands and Works on 29 June 2004, CB(1)2221/03-04(03). See http://www.legco.gov.hk/yr03-04/english/panels/plw/ papers/plw0629cb1-2221-3e.pdf (accessed 13/01/2014).

Massey JB, Pang PLR, Lo JYC and Salisbury D (2007)

Developments in tunnel engineering in Hong Kong. Proceedings of the HKIE Geotechnical Division 27th Annual Seminar, Hong Kong, pp. 137-155.

McLearie DD, Foreman W, Hansmire WH and Tong EKH (2001) Hong Kong Strategic Disposal Scheme Stage I deep tunnels. Proceedings of the Rapid Excavation and Tunnelling Conference 2001, Santiago, USA, pp. 487-498.

Mellors TW and Southcott D (2004) A code of practice for tunnelling. Tunnelling and Underground Space Technology 19(4-5): 335-336.

Pang PLR (2011) Geotechnical control and risk management of tunnel projects in Hong Kong. Proceedings of the International Conference on Tunnelling and Trenchless Technology 2011, Kuala Lumpur, Malaysia, pp. 41-51.

Pang PLR and Woodrow LKR (2009) A new era of tunnel works in Hong Kong: Opportunities, challenges and geotechnical control. Proceedings of the Hong Kong Tunnelling Conference 2009, IOM3 (Hong Kong Branch), Hong Kong, pp. $37-45$.

Sewell RJ, Campbell SDG, Fletcher CJN, Lai WK and Kirk PA (2000) The Pre-Quaternary Geology of Hong Kong. Civil Engineering Department, Geotechnical Engineering Office, Hong Kong.

Sun HW, Chau PKS, Lam TSK and Tsui HM (2012) Knowledge management and development of technical guidance for geotechnical control and risk management of tunnel works in Hong Kong. Proceedings of the HKIE Geotechnical Division 32rd Annual Seminar, Hong Kong, pp. $47-52$.

\section{WHAT DO YOU THINK?}

To discuss this paper, please email up to 500 words to the editor at journals@ice.org.uk. Your contribution will be forwarded to the author(s) for a reply and, if considered appropriate by the editorial panel, will be published as discussion in a future issue of the journal.

Proceedings journals rely entirely on contributions sent in by civil engineering professionals, academics and students. Papers should be 2000-5000 words long (briefing papers should be 1000-2000 words long), with adequate illustrations and references. You can submit your paper online via www.icevirtuallibrary.com/content/journals, where you will also find detailed author guidelines. 